\title{
Dynamics of Tokyo Electric Power Company and the Nikkei: 1985 to 2016 including the Fukushima disaster
}

Serge Rey

CATT, University of Pau, Pau, France

Sophie Nivoix

Université de Poitiers, Poitiers, France

\begin{abstract}
From an asset portfolio management perspective, analyses of the correlations between returns are of great importance. This article investigates the correlations between the rates of return of Tokyo Electric Power Company stock and the Japanese Nikkei index over the lengthy period of 1985 to 2016. Using Markov-switching models, we seek to determine the effects of the Fukushima earthquake disaster compared with those of other shocks on the Japanese financial market. Although the Fukushima catastrophe resulted in more volatile stock prices, it had not changed the correlation structure among asset returns. In addition, both low- and high- volatility regimes, the Nikkei causes Tokyo Electric Power Company, but Tokyo Electric Power Company does not cause the Nikkei.
\end{abstract}

JEL Classification: C24, C32, G00, G01

Keywords: Markov-switching, Stock Market, Japan, Risk, Volatility, Earthquake, Electric Utility Companies

* Corresponding Author: Serge Rey; Department of Economics, CATT, University of Pau, BP576, 64012 PAU Cedex, France, Tel: 33(0)559408063, Fax: 33(0)559408010

Co-authors: Sophie Nivoix; CEREGE EA1722, Université de Poitiers, Faculté de Droit et Sciences Sociales, F-86000 Poitiers, France, E-mail: sophie.nivoix@univ-poitiers.fr 


\section{Introduction}

In environments of uncertainty and market volatility, asset managers must diversify their portfolios, and Japan is no exception. Since the early 1980s, several major shocks have disrupted the Japanese stock market, as reflected in the dynamics of the Nikkei 225 index. The country experienced its first serious financial crisis featuring the collapse of the stock and real estate markets in the late 1980s, followed by the Asian crisis of 1997, the worldwide burst of the Internet bubble in 2000, and the subprime crisis that occurred in 2007. Yet Japan faced an additional shock - the Fukushima earthquake disaster. Although asset markets experience speculative bubble development after crises (Shiller 2005), the Fukushima shock was different; the earthquake and subsequent tsunami resulted in a nuclear catastrophe at least as serious as that of Chernobyl. It had a direct impact not only on Tokyo Electric Power Company (TEPCO) but also on the entire electricity sector, and ultimately the entire economy. Jaussaud et al. (2015) highlight the strong increase in the volatility of stocks in the Japanese electricity sector, reflecting the uncertainty resulted from the shutdown of the Fukushima nuclear reactors.

The current study focuses on the relation between the price of the TEPCO stock and the Nikkei index. We adopt two perspectives for this investigation. First, we discuss the correlations among asset returns. Second, we take a long-term view to investigate whether the Fukushima disaster reveals specific characteristics of the Japanese market that had not been expressed by previous financial shocks.

Like any other company, its stock may be affected by business or economic events, but it is possible that specific environmental and nuclear safety issues (Fukushima catastrophe) have had specific impacts on the stock volatility and returns of TEPCO, a major electric and nuclear power utility. We investigate the correlations between the Japanese stock market index and the stock price of TEPCO using a Markov Regime Switching (MRS) technique. To our knowledge, this study is the first comprehensive econometric analysis of the market valuation of this basic network firm.

Abundant literature shows that the regime switching Generalized Autoregressive Conditional Heteroscedasticity (GARCH) model outperforms other GARCH models, such as Günay's (2015) oil return study. Marcucci (2005) concludes that the MRSGARCH model exhibits better fitting results than other GARCH models, particularly in the short run, whereas most GARCH models are more adapted to long-run modeling. Boudt et al. (2012) find strong evidence of time variation within the regime volatility of 
US deposit banks' stock returns for 1994 2011.

By studying the impacts of several earthquakes in Japan, Hatase et al. (2013) show that the Great Kanto earthquake in 1923 had more impact on the volatility of the yen than the Great Hanshin-Awaji earthquake in 1995 or the Great East Japan earthquake in 2011. Moreover, in a study of 2010 2012, Jaussaud et al. (2015) show that following the Fukushima earthquake, regime switching occurred in the form of shifting from a low- to a high-volatility regime for at least a year after the catastrophe.

Although studies of regime switching and volatilities are plentiful, we focus on another important pattern, the existence of nonlinear relations among different stock returns as well as between stock returns and volatilities. We can analyze these nonlinearities with two categories of regime-shift models. First, we consider a regimeswitching dynamic correlation model (Pelletier 2006). Second, we estimate a MarkovSwitching Vector Autoregression (MS-VAR) (Krolzig 1997) model to clarify the relations among stock price returns. Third, we analyze the dynamic interaction between the TEPCO price and the price of the Nikkei 225 index. Following Ehrmann et al. (2003), we retain impulse response functions computed from an MS-VAR model in which the regimes do not switch beyond the shock horizon. As Hamilton (1989) notes, the state variable that controls the regime is exogenous. In the case of TEPCO, exogenous factors include the general economic situation, factors that drive the electric utility industry, or certain regulatory or environmental changes such as earthquakes. With regard to the Nikkei index, the exogenous factors entail Japanese interest rates, exchange rates, and political and environmental issues.

The remainder of this paper is organized as follows: Section II presents the data and methodology, Section III analyzes the stationarity of series, Section IV details the correlation structure between TEPCO and the Nikkei index, Section V presents the MSVAR model, and Section VI concludes. 


\section{Data}

This study investigates the behaviors of daily prices and returns of TEPCO and the Nikkei 225 over a 30-year period from June 19, 1985 to March 29, 2016. The financial and stock market data consist of 8,016 observations drawn from the International Factset database. As Figure 1 shows, the long-term Nikkei 225 index and the TEPCO stock price show high volatility between 1985 and 2016.

Some shocks such as those from the 1987 market crash, the Gulf War, the burst of Japan's real estate bubble at the beginning of the 1990s, the burst of the Internet bubble in 2000 and the subprime crisis in 2008 have had an impact on the entire Japanese financial market. The Nikkei never climbed back to its 1990 high (more than twice its 2016 level), and TEPCO exhibited the same pattern until the Fukushima disaster. Nevertheless, after this catastrophe, the behaviors differ. After its fall, TEPCO's stock price represented less than $5 \%$ of its highest value, in 1987, while the Japanese market seemed to absorb the shock more easily.

Figure 1. TEPCO and Nikkei 225 index

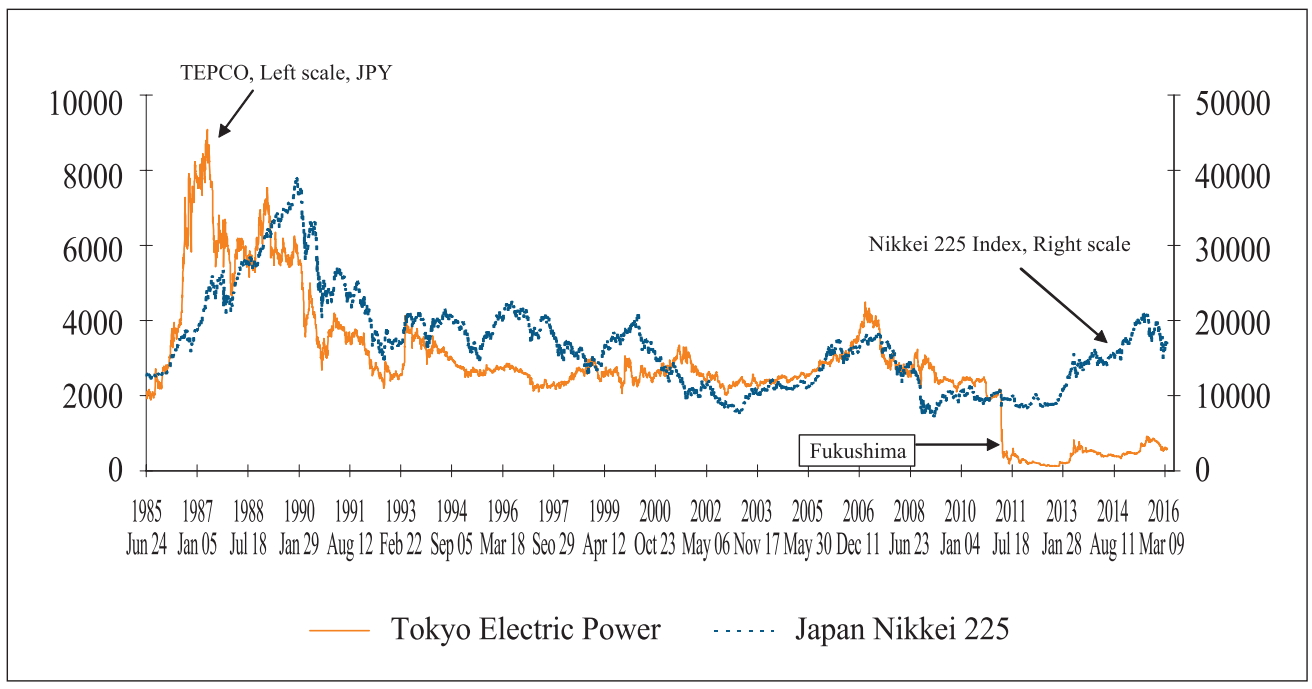

(Source) International Factset database 
We complete our analysis with descriptive statistics of daily stock returns. At the industry level, daily returns $R_{t}$ are defined by $R_{t}=100 \operatorname{Ln}\left(P_{t} / P_{t-1}\right)=100 \Delta \operatorname{Ln} P_{t}$, where $P$ represents the stock price or market index. As Figure 2 shows, the largest daily returns of the Nikkei 225 occurred during the 2008 subprime crisis; the second-largest variations occurred during the Gulf War in 1990. For TEPCO, the largest volatility appeared during the weeks after the Fukushima earthquake and continued for a few years. The only other period in which the company experienced such dramatic price variations was during the months following the 1987 market crash.

Figure 2. Daily returns on TEPCO and the Nikkei 225

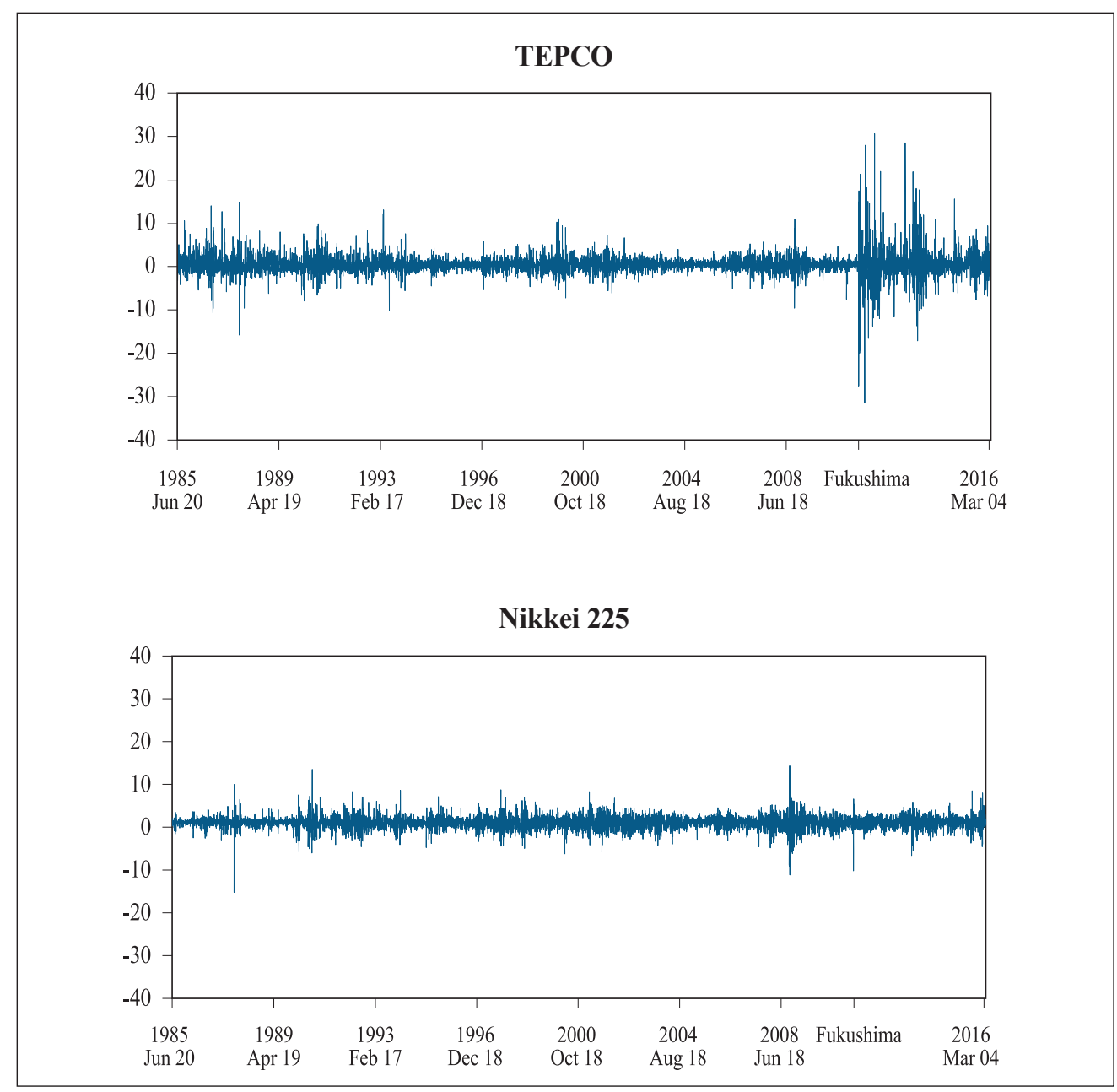

(Source) International Factset database, calculations of authors 
Table 1 reports the descriptive statistics for the natural logarithms of TEPCO and the Nikkei 225 (columns 1 and 3) as well as for the TEPCO and Nikkei returns (columns 2 and 4). It reveals the partial differences in the main patterns for TEPCO and the Nikkei index. Whereas the median return is 0 for both, the mean value is -.0154 for TEPCO and .0036 for the Nikkei. In the long run, the standard deviation of TEPCO stock is far higher than that of the Nikkei. The difference is more obvious when we account for kurtosis, which indicates that TEPCO (35.49) has experienced many larger price variations than the Nikkei during the past three decades. Moreover, return distributions are not symmetric; there are positively skewed returns for TEPCO and negatively for the Nikkei. As a consequence, both return distributions as confirmed by the high values of the Jarque-Bera statistic, do not fit a Gaussian distribution. The normality hypothesis is rejected at the $1 \%$ significance level. This result is fairly common in international market returns (Cont 2001), but in the Japanese context, it is interesting to look more deeply at the volatility process.

\section{Table 1. Descriptive statistics}

(1985 2016)

\begin{tabular}{|l|c|c|c|c|}
\hline \multirow{2}{*}{} & \multicolumn{2}{|c|}{ TEPCO } & \multicolumn{2}{c|}{ Nikkei 225 } \\
\cline { 2 - 5 } & $(1)$ & $(2)$ & $(3)$ & $(4)$ \\
\cline { 2 - 5 } Mean & Ln P & $1004 \operatorname{Ln} P$ & $\operatorname{Ln} P$ & $1004 \operatorname{Ln} P$ \\
\hline Median & 7.69085 & -0.0154 & 9.6588 & 0.0036 \\
\hline Maximum & 7.8761 & 0.0000 & 9.6955 & 0.0000 \\
\hline Minimum & 9.1133 & 30.61160 & 10.5691 & 13.2346 \\
\hline Standard Deviation & 4.7957 & -32.3273 & 8.8614 & -16.1354 \\
\hline Skewness & 0.8642 & 2.3873 & 0.3626 & 1.4458 \\
\hline Kurtosis & -1.5357 & 0.3443 & 0.1201 & -0.2875 \\
\hline Jarque-Bera & 4.9376 & 35.4962 & 2.4529 & 11.0741 \\
\hline Q(1) & $4404.93^{* * *}$ & $352864.5^{* * *}$ & $119.2268^{* * *}$ & $21884.74 * * *$ \\
\hline Q(4) & $8010.7 * * *$ & $45.601 * * *$ & $8005.9 * * *$ & $6.8197 * * *$ \\
\hline ARCH(1) & $31990^{* * *}$ & $90.686^{* * *}$ & $31958^{* * *}$ & $20.703^{* * *}$ \\
\hline ARCH(4) & $1109.964 * * *$ & $1018.342^{* * *}$ & $279.4912^{* * *}$ & $271.1421^{* * *}$ \\
\hline Observations & $1250.079^{* * *}$ & $1191.541^{* * *}$ & $999.8653^{* * *}$ & $999.3685^{* * *}$ \\
\hline
\end{tabular}

(Note) $* * *$ Significance at the $1 \%$ level, thereby rejecting the null hypotheses of normally distributed errors, of no serial correlation, and of no ARCH effects. 
Table 1 also provides the Ljung-Box first $(\mathrm{Q}(1))$ and fourth $(\mathrm{Q}(4))$ autocorrelation tests and the first $(\mathrm{ARCH}(1))$ and fourth $(\mathrm{ARCH}(4))$ Language Multiplier (LM) tests for autoregressive conditional heteroskedasticity. ${ }^{1}$ For the levels and differences of both series, we find evidence of first and fourth autocorrelation. As Jaussaud et al. (2015) point out with regard to TEPCO, such autocorrelations can signal momentum effects. In the same way, ARCH-LM tests confirm the presence of ARCH effects in the time series residuals (rejecting the null hypothesis of no $\mathrm{ARCH}$ effects).

We complete the data description by examining the linearity of stock prices. The Likelihood Ratio (LR) test is based on the LR statistic (Garcia and Perron 1996, Krolzig 1997):

$$
L R=2\left(\operatorname{Ln} \ell_{M S-A R}-\operatorname{Ln} \ell_{A R}\right)
$$

where $L n \ell_{M S-A R}$ and $L n \ell_{A R}$ denote the log-likelihoods of the MS-AR and Autoregressive (AR) models. The null hypothesis is that there is no regime shift. The results in Table 2 confirm the rejection of the null hypothesis for the stock prices and returns of TEPCO and the Nikkei 225. This conclusion is valid when we use the Bayesian Information Criterion (BIC) to choose the lag length.

Table 2. Linearity test results

\begin{tabular}{|c|c|c|c|c|c|}
\hline \multicolumn{6}{|c|}{$L R$ test of $A R$ model (null) versus $M S-A R$ model (alternative) } \\
\hline & & Lag & $\operatorname{Ln} \ell(A R(p))$ & $\operatorname{Ln} \ell(M S(2)-A R(p))$ & $L R$ statistic \\
\hline \multirow{4}{*}{ TEPCO } & \multirow{2}{*}{$\operatorname{Ln} P$} & 1 & 18563.50 & 18984.14 & $841.28 * * *$ \\
\hline & & $3 \psi$ & 18590.64 & 19280.94 & $1380.60 * * *$ \\
\hline & \multirow{2}{*}{$100 \Delta \operatorname{Ln} P$} & 1 & -18324.37 & -17594.46 & $1459.86^{* * *}$ \\
\hline & & $4^{\psi}$ & -18296.32 & -17547.89 & $1496.86^{* * *}$ \\
\hline \multirow{3}{*}{$\begin{array}{c}\text { Nikkei } \\
225\end{array}$} & $\operatorname{Ln} P$ & $1 \%$ & 22584.37 & 22706.41 & $244.08^{* * *}$ \\
\hline & \multirow{2}{*}{$100 \Delta \operatorname{Ln} P$} & 1 & -14324.33 & -14093.05 & $462.56^{* * *}$ \\
\hline & & $2 \psi$ & -14317.31 & -14000.51 & $633.60 * * *$ \\
\hline
\end{tabular}

(Note) $* * *$ indicates that the null hypothesis of no regime shift is regime shift is rejected at the $1 \%$ significance level.

$\psi$ Lag determined from the BIC.

\footnotetext{
${ }^{1}$ The presence of ARCH effects in the residuals can be tested with the model $y_{t}=\mu+\varepsilon_{t}$, where y represents alternatively the log of the stock price or the log difference of the price series. With a prediction of no ARCH effects, the test statistic is $L M=T R^{2} \sim \chi^{2}(p)$, where $T$ is the sample size and $R^{2}$ is computed on the basis of an $A R(p)$ process for $\varepsilon_{t}^{2}$.
} 


\section{Stationarity of Series}

\section{A. Determination of breaks}

To verify the stationarity of the stock prices and returns, we rely on unit root tests. However, to the extent that significant events occurred during this period, it is possible that breaks appeared in these series. For this reason, we test for the presence of breaks. Following Bai and Perron (1998, 2003a, 2003b), we use a multiple linear regression with $m$ breaks:

$$
y_{t}=x_{t}^{\prime} \beta+z_{t}^{\prime} \delta_{r}+u_{t}
$$

where $t=T_{r-1}+1, \ldots, T r$, for $r=1, \ldots, m+1$, and $y$ represents the $\log$ or $\log$ difference, of price series. We treat the breaks $\left(T_{1}, \ldots, T_{m}\right)$ as unknown; $x_{t}(p \times 1)$ and $z_{t}$ $(q \times 1)$ are vector covariates. In addition, because $T=8016$, we use a trimming value of $\varepsilon=.05$. For $p=0$, we present the model estimation for two cases: with only a constant as a regressor (i.e., $z_{t}=\{1\}$ ), and for an $A R(1)$ structure (i.e., $z_{t}=\left\{1, y_{t-1}\right\}$ ).

Bai and Perron (1998), proposed three tests. The first considers that the number of breakpoints is not known. It is a double test of no break against an unknown number of breaks given some upper bound M. These are called the double maximum tests (Bai and Perron, 2003c p.14), since it involves maximization both for a given breakpoint and across various values of the test statistic for the breakpoint. This test permits to verify if there is at least one structural break. We calculate the UDmax and WDmax statistics. UDmax is the unity double maximum test in which the likelihood weights of each number of breaks is equal to 1 , and the WDmax includes different weights that load the likelihoods of these numbers of breaks (depending on $q$ values).

The other two tests assume pre-defined breaks. On one side, we have a test of the null hypothesis of no structural break $(m=0)$ versus $m=r$ breaks, labelled $\operatorname{Sup} F_{T}$. On the other side, there is the test of $l$ versus $l+1$ breaks, labelled $\operatorname{Sup} F_{T}(l+1 \mid l)$. Estimates are performed using the sequential method supplemented by the use of the BIC and a modified Schwarz criterion (LWZ).

The results are in Table 3. UDmax and WDmax tests confirm that the null hypothesis of no structural break is clearly rejected at the $5 \%$ error level when the alternative hypothesis is two breaks, with the exception of the rate of return of TEPCO in the model 
with only the constant, as well as for the return of the Nikkei in the $A R(1)$ model with UDmax.

With regard to the two estimates of Equation (2), the three tests and criteria indicate the presence of two to five breaks for the TEPCO stock returns. In addition, for the Nikkei 225, the sequential test shows one break in the stock return variable across both models. For the log prices, we obtain at least two breaks for all estimates. 


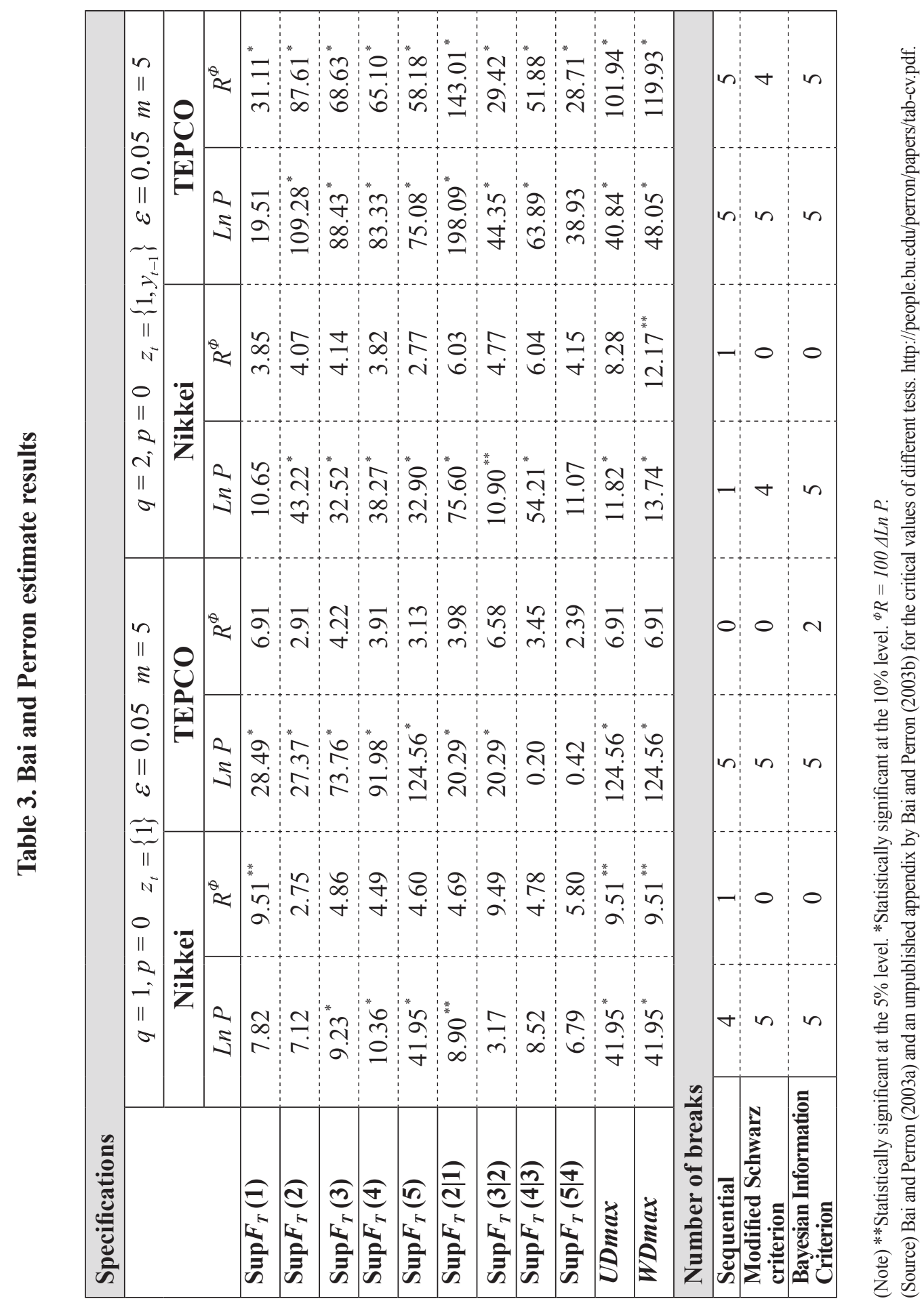




\section{B. Unit root tests}

To consider the presence of breaks, we use two unit-root tests: (1) Lumsdaine and Papell's (LP) (1997) test, which allows two breaks under the alternative hypothesis of the unit root test, and (2) the Lee-Strazicich Lagrange Multiplier (LM) test (2003), which assumes two endogenous breaks for both the null and alternative hypotheses. The LP test involves a modified version of the augmented Dickey-Fuller test with two endogenous breaks. The model of stock returns $(R)$ can then be written as

$$
\Delta R_{t}=\mu+\beta t+\theta D_{1 t}++\omega D_{2 t}+\alpha R_{t-1}+\sum_{i=1}^{k} c_{i} \Delta R_{t-i}+\varepsilon_{t}
$$

where $D_{1}$ and $D_{2}$ are dummy variables that capture structural changes in the intercept at times $T B_{1}$ and $T B_{2}$, respectively. The optimal lag length $(k)$ is determined on the basis of a general-to-specific approach $(t$-test, $k \max =10)$. The unit root hypothesis is that $\alpha=0$. For the two stock returns (Table 4), the null hypothesis is rejected at the $5 \%$ level, confirming the stationarity of $R$.

Next, the LM unit root test statistic is generated from the following regression:

$$
\Delta R_{t}=\delta^{\prime} \Delta Z_{t}+\phi \widetilde{S}_{t-1}+u_{t}
$$

where $Z$ is a vector of exogenous variables, such that $Z_{t}=\left[1, t, D_{1 t}, D_{2 t}\right]$ with $D_{1 t}$ and $D_{2 t}$ as shift dummies (crash model), and $\widetilde{S}$ denotes the detrended series, such that $\widetilde{S}_{t}=R_{t}-\widetilde{\psi}_{x}-Z_{t} \widetilde{\delta}$. In addition, $\widetilde{\delta}$ are coefficients in the regression of $\Delta R_{t}$ on $\Delta Z_{t}$ , and $\widetilde{\psi}_{x}$ is given by $R_{1}-Z_{1} \widetilde{\delta}$ (Lee and Strazicich 2003). The LM test statistic is the $t$-ratio that checks the null hypothesis that $\phi=0$. The results of the LM tests in Table 4 confirm the conclusions of the LP tests, though the selected break dates are different. The two stock returns are stationary.

With regard to rates of return, the Nikkei 225 has been deeply influenced by global economic events, such as the real estate crash in Japan in the early 1990s, the Internet bubble burst in 2001, and the subprime crisis in 2008. In contrast, TEPCO has been affected more by the stock market crash in 1987, the Asian crisis in 1997, and the Fukushima catastrophe in 2011. 


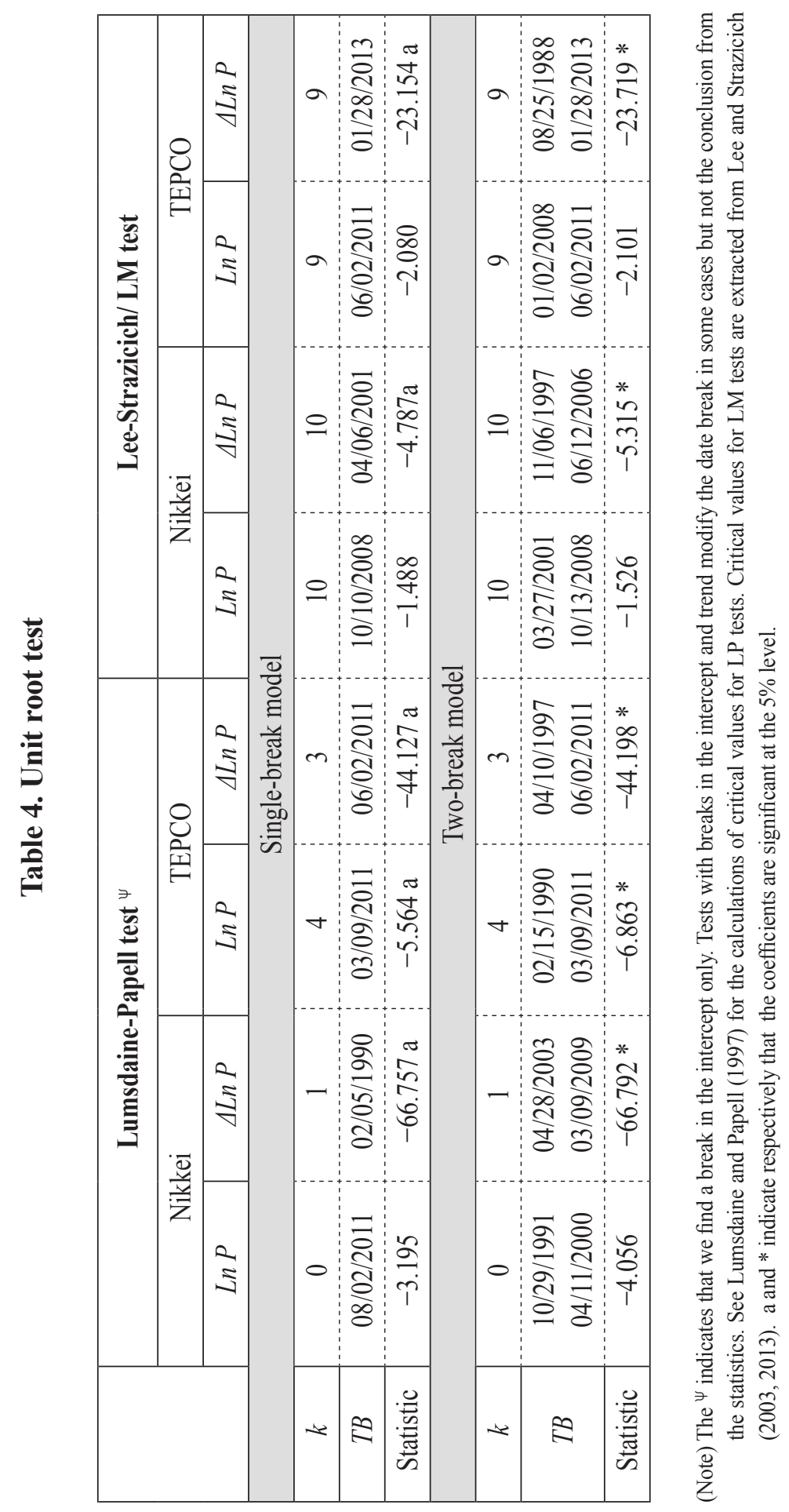




\section{The TEPCO-Nikkei Correlation}

The correlation among changes in equity prices, or asset returns, constitutes an essential element of decision-making for portfolio asset allocation. In particular, we seek to verify, from the correlation between the returns of TEPCO and the Nikkei, whether the various shocks that have occurred since the 1980s have had comparable effects, or if conversely some specificity relates to the Fukushima disaster. For this purpose, we propose three correlation measures: a rolling correlation of daily changes, an asymmetric dynamic conditional correlation, and a correlation with regime switching.

\section{A. Rolling centered correlation}

Figure 3 shows large variations in the one-year rolling correlations between TEPCO stock and the Nikkei by time period. The shaded (gray) zone corresponds to the postFukushima period.

The high correlation $(>0.60)$ relates to major economic or financial events, such as the 1987 stock crash, the real estate crash in the early 1990s, the 2008 subprime crisis, and to a lesser extent, the Fukushima earthquake. The earthquake is associated mainly with a low correlation, because TEPCO was impacted far more than other listed companies. Three years after the nuclear accident, the correlation shifted back toward its usual value - that is, close to 0.40 . The correlation rarely has been below 0.2 ; In general, the general macroeconomic and market parameters influence all listed firms including TEPCO. The only time the correlation was negative was during the Internet bubble (2000 2001), an occurrence that can be explained by the specific characteristics of that stock market overvaluation. That is, stock market and Nikkei increases were driven by high-tech and internet-related firms, whereas TEPCO activity was not affected by these technological and market changes. 


\section{Figure 3. One-year rolling correlation}

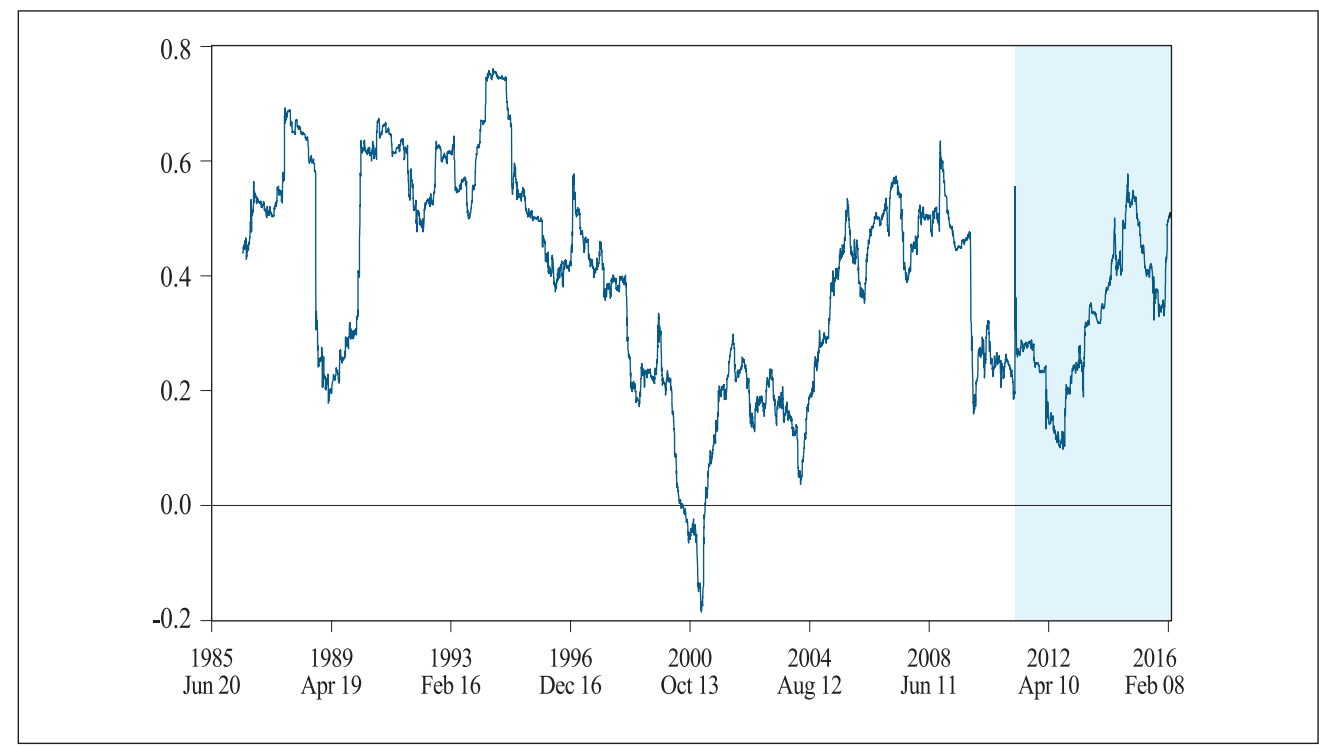

(Note) Rolling correlation between daily changes in TEPCO price and Nikkei indexes

\section{B. Dynamic conditional correlation}

While the rolling correlation provides a first indication of the interdependence between daily changes in TEPCO and Nikkei, it does not take into account the possibility of asymmetry in volatilities. The large shocks in the Japanese financial market (Figure 2) and the measures of conditional variances (Appendix 1) confirm the so-called asymmetry phenomenon, where volatility increases more after a negative shock than after a positive shock. Consequently, this asymmetry will be present in conditional correlations.

Following Engle (2002) and Capiello et al. (2006), we use conditional volatilities to calculate the conditional correlation between TEPCO and the Nikkei 225. By allowing for conditional asymmetries in correlations, we adopt the Asymmetric Generalized Dynamic Conditional Correlation (AG-DCC) (Capiello et al. 2006). This process allows this phenomenon to be taken into account and thus provides a more accurate observation of the correlations between daily returns. Figure 4 depicts the dynamic correlations, which we use to answer two key questions: Did the Fukushima catastrophe modify the correlation between TEPCO and the Japanese stock market? What have 
been the consequences of changes in the correlation from the perspective of portfolio diversification?

The results show a mean reversion after 2011; there is an increase in the correlation after the Fukushima catastrophe, just as after the real estate crash in the early 1990s and the Internet bubble burst in 2001, as well as before the 1987 stock market crash and the 2008 subprime crisis.

The AG-DCC figure exhibits values that, on average, are slightly smaller than those of the rolling daily correlation between TEPCO and the Nikkei 225.

\section{Figure 4. Conditional correlation: AG-DCC model}

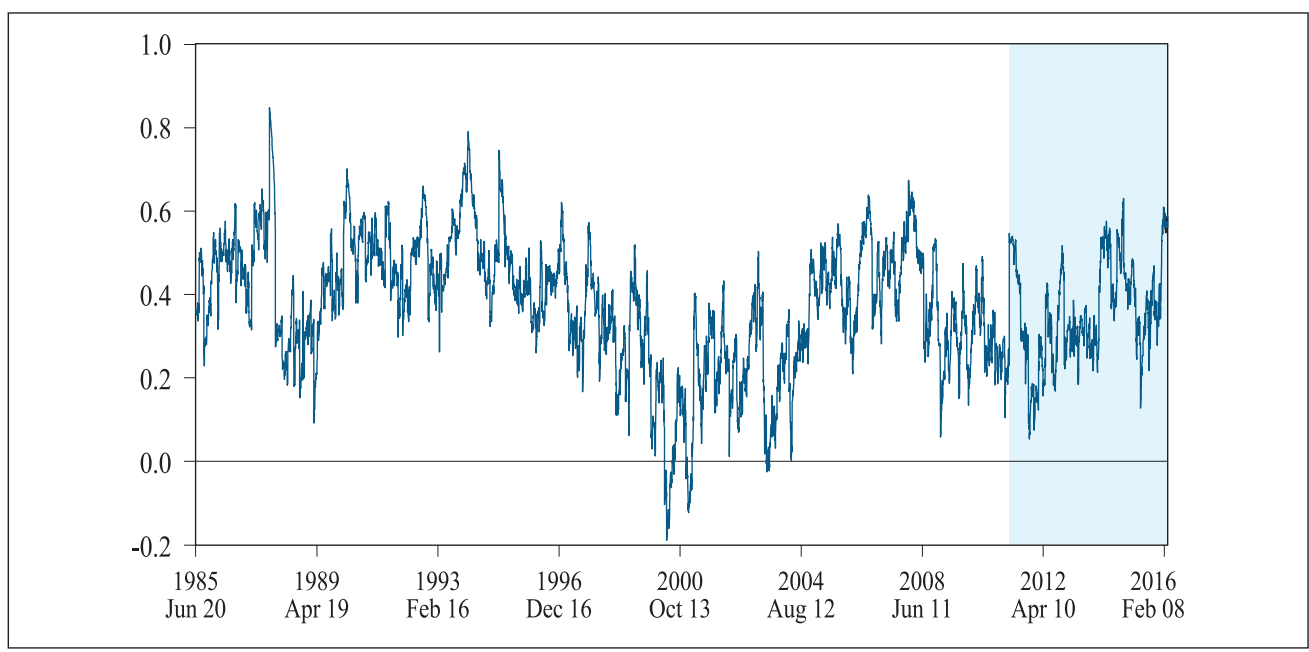

(Note) Conditional correlation between TEPCO and Nikkei returns

The results in Figure 4 have several implications for investment strategizing and portfolio diversification. If the correlation is high, including TEPCO in a portfolio does not improve diversification compared with investing in a Nikkei tracker or any Japanese market-mimicking portfolio. If the correlation is low, investing in a firm such as TEPCO is fruitful in terms of diversification and risk reduction. The weeks just after Fukushima catastrophe, when TEPCO stock dropped sharply, thus a recovery by TEPCO could confer two advantages - increased stock value and a moderation of risk levels - because the firm is now backed by the state. Moreover, in terms of sector diversification, TEPCO is still the country's foremost electric producer, whatever the future energy policy of Japan. As a consequence, it remains a compelling option for any investor interested in the Japanese energy industry. 


\section{Markov-switching dynamics}

Generally, the strategy of diversification depends on the degree of correlation between stocks and/or between stocks and the market index on the whole. From this perspective, we consider both the correlations between the volatilities and the relation between the returns of TEPCO and the Nikkei. Our observation of volatilities reveals two insights (Appendix 1). First, during the global crisis period and especially after the earthquake, the behaviors of TEPCO and the Nikkei differ. Second, we find asymmetric responses to shocks (GARCH estimations) and alternation between high- and low-volatility periods. To account for these characteristics, we address the potential conditional correlation of TEPCO stock with the Nikkei using the regime-switching dynamic correlation model of Pelletier (2006). ${ }^{2}$ We used a $k$-variate process, where $Y_{t}=H_{t}^{1 / 2} U_{t}$, and $U_{t}$ is an i.i.d $\left(0, I_{K}\right)$ process. The time-varying covariance matrix $H_{t}$ can be written as $H_{t}=S_{t} \Gamma_{t} S_{t}$ , such that $\Gamma_{t}$ contains the correlations, and $S_{t}$ is a diagonal matrix of the standard deviations. This model exhibits a dynamic correlation since it admits regime switching of different correlation levels according to a Markov chain process. If we look at the two-state regime-switching model, we can determine the probabilities of being in a high correlation regime and a low correlation regime, respectively. Thus, Figure 5 shows the probability of being in a regime of low (high) correlation on the upper (bottom) graph. Therefore, we can distinguish between a high-correlation regime in the middle of the 1980s, during the 1990s, and after the dot-com crisis, but not after the earthquake, which confirms the divergent reactions of TEPCO and the Nikkei 225.

See also Billio and Caporin (2005). 


\section{Figure 5. Smoothed probabilities of the two-regime model}

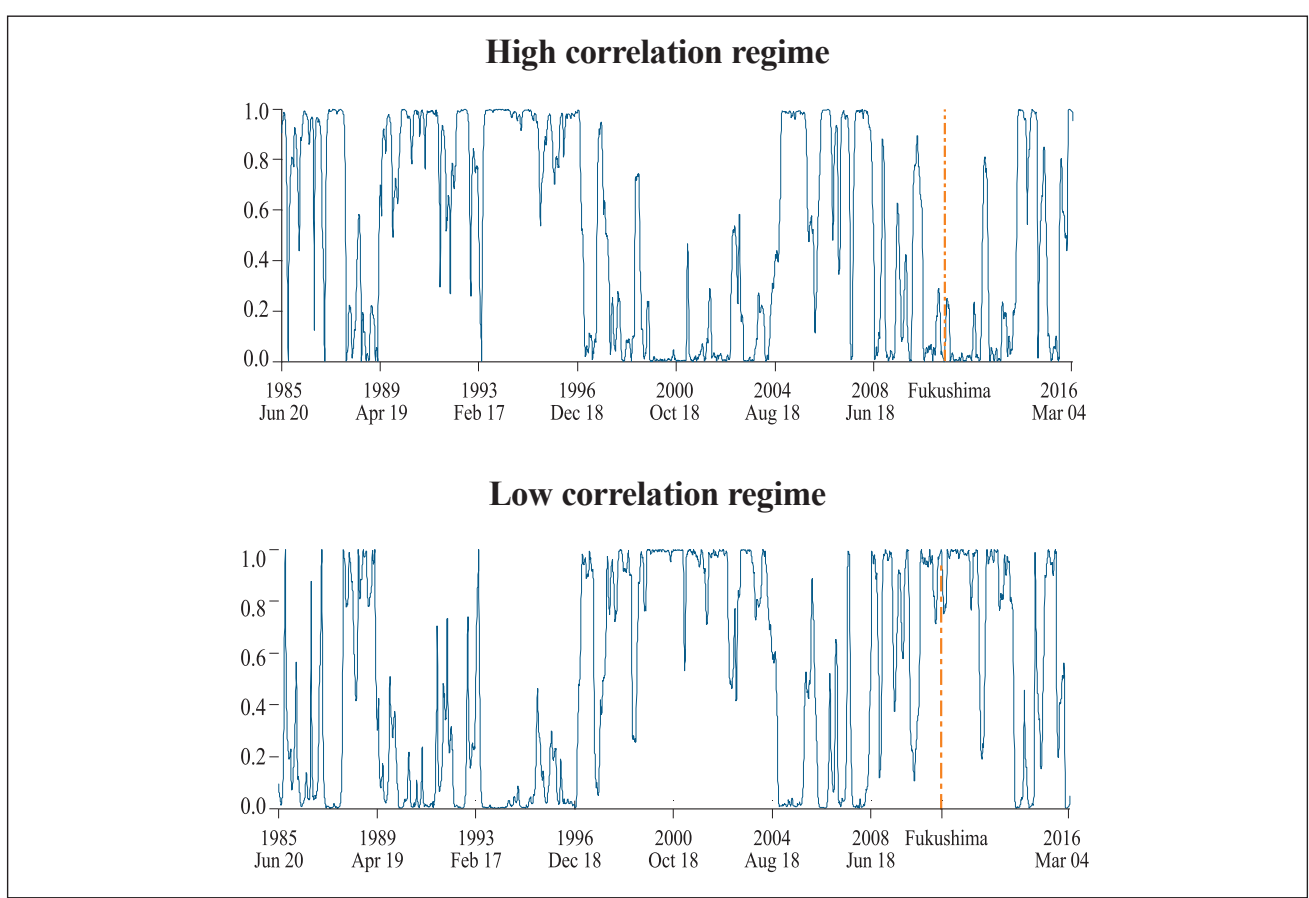

(Note) Regime switching dynamic correlation model with two regimes

Meanwhile, there were two lengthy periods in which the low-correlation regime dominated: 1997 2004 and 2008 2014. The first period includes the failure of Long-Term Credit Bank in 2001 and the effects of the burst of the Internet bubble in 2002. The second begins with the subprime crisis and includes the Fukushima catastrophe and the economic and electrical power consequences. We can conclude that these results point to the relevance of regime-switching models for the TEPCO-Nikkei correlation. To investigate this relation more deeply, in Section V, we explore the Markov-Switching Vector Error Correction (MS-VEC) model, which allows the variable response to regime fluctuations.

\footnotetext{
${ }^{3}$ When we analyze the regime-switching correlation model with three states (Appendix 2), we find that the high-correlation regime has been the most frequent for TEPCO during the past 30 years. The momentum effect thus was more frequent than the mean-reverting effect among the return patterns. The medium-correlation regime is not very frequent, and the low-correlation regime is even less so.
} 


\section{Markov-switching Vector Autoregressive Model}

We investigate the relation between the rates of return of TEPCO and the Nikkei index. Traditionally, a Vector Autoregressive (VAR) model (Sims 1980) would analyze the relations among endogenous variables. But "if the time series are subject to shifts in regime, the stable VAR model with its time invariant parameters might be inappropriate " (Krolzig 1997, p.11). Therefore, the use of an MS-VAR is preferable. Owing to nonstationary stock prices ( $\mathrm{LnP}$, Table 4$)$, the possible cointegration relation between TEPCO share price and the Nikkei index lead us to consider an MS-VEC model. Before estimating this model, we must test for the presence of cointegration between the loglevel of the stock prices (Table 5). First, we apply the Johansen $(1988,1996)$ standard test. Second, following Johansen et al. (2000) and Joyeux (2007), we account for the possibility of breaks in the series, especially after the earthquake (Figure 1) and adopt a VAR model with structural breaks.

A trace test finds one cointegration vector at the .05 level when we include a dummy variable for the Fukushima catastrophe $\left(D_{F}\right)$.

Table 5. Johansen cointegration tests

\begin{tabular}{|c|c|c|c|}
\hline \multicolumn{4}{|c|}{ Standard model } \\
\hline $\mathrm{H}_{0}$ & Trace Statistic & Critical value $(0.05)$ & $p$-value ${ }^{\psi}$ \\
\hline$r=0$ & 5.69 & 20.16 & 0.9547 \\
\hline$r \leq 1$ & 1.77 & 9.14 & 0.8167 \\
\hline \multicolumn{4}{|c|}{ Model with break } \\
\hline$r=0$ & 31.29 & 24.88 & $0.0058 * *$ \\
\hline$r \leq 1$ & 3.10 & 12.11 & 0.7919 \\
\hline \multicolumn{4}{|c|}{ Normalized Cointegrating coefficients } \\
\hline LnTEPCO & & & $D_{F}$ \\
\hline 1.000 & & $\begin{array}{l}96 \\
57)\end{array}$ & $\begin{array}{c}2.1135 \\
(0.1384)\end{array}$ \\
\hline
\end{tabular}

(Note) ${ }^{\psi}$ MacKinnon, Haug, and Michelis's (1999) $p$-values. On the basis of the BIC, we retain three lags for each model. ** Rejection of the hypothesis at the 5\% level; standard errors are in parentheses. To conserve space, we omit results with max eigenvalue statistics that give the same conclusions. 
The cointegration relation (Table 5) confirms that in the long run, an increase of the Nikkei index by $1 \%$ leads to a $.82 \%$ increase in TEPCO's price, thus the earthquake has a negative impact on the stock price. The use of a MS-VEC model is therefore relevant for studying the interactions between the TEPCO stock returns and the Nikkei index returns.

\section{A. Markov-switching vector error correction model}

The general idea behind the Markov-switching model is that the parameters of the underlying data-generating process of the observed time series vector $X_{t}$ depend on the unobservable regime/state variable $s_{t}$. If we define the time series vector $X_{t}=\left[\right.$ LnTepco $_{t}$, LnNikkei $\left._{t}\right]$, the MS-VEC model with $s=1, \ldots, M$ states and $p$ lags is given by:

$$
\Delta X_{t}=\delta\left(s_{t}\right)+A_{1}\left(s_{t}\right) \Delta X_{t-1}+\ldots+A_{p}\left(s_{t}\right) \Delta X_{t-p}+\Pi_{s_{t}}\left[X_{t-1}, D_{F t-1}\right]^{\prime}+\varepsilon_{t}
$$

with $\varepsilon_{t} / s_{t} \sim N I D\left[0, \sum\left(s_{t}\right)\right]$, and $\sum$ a positive definite covariance matrix.

Here, $A_{i}$ is the coefficient matrix, and $\Pi_{s_{t}}$ is the matrix that contains the long-run relation between the TEPCO stock price and the Nikkei index, with $\Pi_{S_{t}}=\alpha_{s_{t}} \beta^{\prime}$. In turn, $\beta$ represents the coefficients of the long-run effects that do not change over the entire period, $\alpha_{s_{t}}$ is the regime-dependent coefficient, and $\alpha_{s_{t}}$ reveals the coefficients that indicate how endogenous variables respond to the disequilibrium. That is, the speed at which the variables adjust to the long-run equilibrium relation across regimes. For example, the effect of a shock in the TEPCO price on the Nikkei index depends on whether the financial market is subject to high or low volatility.

However, the regime variable $s_{t}$ is assumed to follow an $M$-state Markov chain. The probability of being in regime $j$ in the next period is conditional on the current regime $i$, which we assume is constant and exogenous. If $\operatorname{Pr}\left(s_{t+1}=j \mid s_{t}=i\right)=p_{i j}$, the transition probabilities matrix $P$ can be defined as follows:

$$
P=\left[\begin{array}{cccc} 
& s_{1} & \cdots & s_{M} \\
s_{1} & p_{11} & \cdots & p_{1 M} \\
\vdots & \vdots & \vdots & \vdots \\
s_{M} & p_{M 1} & \cdots & p_{M M}
\end{array}\right] \quad \text { with } \sum_{j=1}^{M} p_{i j}=1
$$


Using this model, we can study the relations among stock returns, and analyze the regime-dependent impulse response function (Ehrmann et al. 2003).

\section{B. Empirical results}

The parameters of the Markov-switching model are obtained with a Bayesian Markov chain Monte Carlo estimation, based on Gibbs sampling. Hahn et al. (2010) and Rey et al. (2014) present a technical explanation of this method. Balcilar et al. (2015) select this approach to study the response of stock prices to a shock in oil prices in an MS-VEC model. We adopt a similar approach and use the RATS code based on their paper.

The model is estimated for the cases of two regimes, a high-volatility regime (Regime 1) and a low-volatility regime (Regime 2 ). The transition probability matrix for high- and low-volatility regimes is as follows:

$$
P=\left[\begin{array}{ll}
0.9466 & 0.2377 \\
0.0534 & 0.7623
\end{array}\right]
$$

The first column indicates that the high-volatility regime is fairly stable and does not switch frequently to a low-volatility regime (probability of 5.34\%). Comparatively, the low-volatility regime is less persistent; it switches to high-volatility with a probability of $23.77 \%$ (second column). Table 6 expands on these results, specifying the characteristics of the two regimes.

Table 6. Regime properties

\begin{tabular}{|l|c|c|c|}
\hline & Probability & Observations & Duration (days) \\
\hline $\begin{array}{l}\text { Regime 1 } \\
\text { (high volatility) }\end{array}$ & 0.8167 & 6683 & 18.7412 \\
\hline $\begin{array}{l}\text { Regime 2 } \\
\text { (low volatility) }\end{array}$ & 0.1833 & 1331 & 4.2058 \\
\hline
\end{tabular}

The duration of the high-volatility regime is 18.74 , or almost one month in the markets, given that there are normally 22 trading days in a month. Therefore, the momentum effect is substantial when volatility is high. In contrast, the low-volatility regime tends to create a faster reversion to the mean, because the duration is only 4.2 
days. The high-volatility regime thus tends to stay high for a long time; the low-volatility regime tends to have a shorter time span and switches more frequently to high-volatility than the reverse. This asymmetric response to volatility shocks implies that risk aversion is difficult to include in a long-run portfolio strategy in this market.

Figure 6 plots the estimates of the smoothed probability of the high-volatility Regime 1. Over the entire period, we find several periods of high volatility. The 1980s are dominated by high volatility, especially after 1985 and around 1990. Beginning with the Asian crisis of 1997 to 1998, Regime 1 dominates until the burst of the Internet bubble. Regime 1 also dominates during the subprime crisis and after the Fukushima disaster. After this most recent shock, Regime 1 appears to be the most durable. Conversely, the low-volatility Regime 2 appears to dominate only in the mid-1990s, the 2000s, and during the two years preceding the great earthquake.

Figure 6. Smoothed probability of high-volatility regime

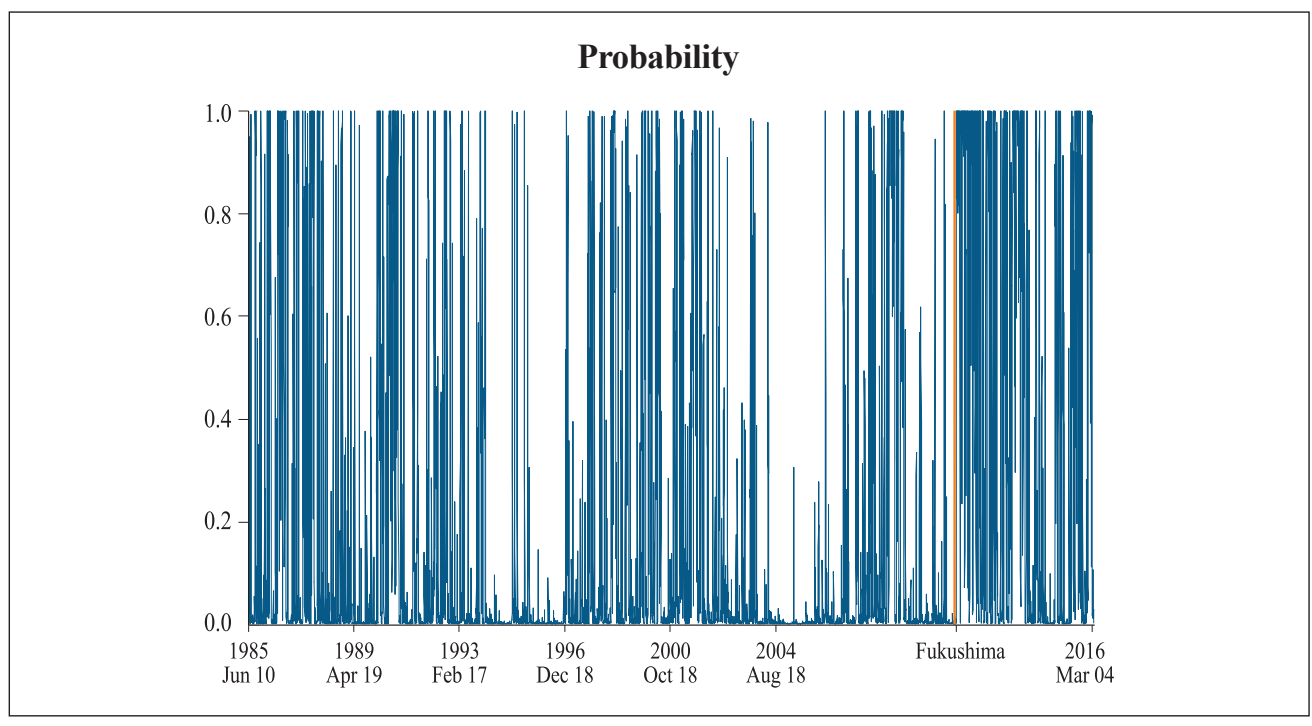




\section{Impulse response functions}

Because "The regime-dependent impulse response function describes the relation between endogenous variables and fundamental disturbances within Markov-switching regime" (Ehrmann et al. 2003, p. 297), such an analysis is interesting for TEPCO, as its stock returns were affected by both endogenous and fundamental events. For regime $i$ and the $k$ endogenous variables, the impulse function response of the endogenous variable can be written as follows:

$$
\left.\frac{\partial E_{t}\left[\Delta X_{t+h}\right]}{\partial u_{k, t}}\right|_{s_{t}=\ldots=s_{t+h}=i}=\theta_{k i, h} \text { at horizon } t+h \text { with } h \geq 0
$$

We consider a one standard deviation shock to the $k^{\text {th }}$ fundamental disturbance in volatility at time $t\left(u_{k, t}\right)$, where $k$ represents the Nikkei index or the TEPCO stock, respectively. We analyze the case of a shock on the Nikkei and then the case of a shock on TEPCO. Figures 7 and 8 plot the 20-day impulse responses of a one standard deviation shock. Impulse responses appear as solid lines (IRF) and 95-percent confidence intervals appear as dotted lines (LOWER and UPPER). If we consider a shock in the Nikkei, the responses of the Nikkei and TEPCO are positive, regardless of the regime. However, the standard deviations increase strongly in the high-volatility regime, with stronger responses than in the low-volatility regime. This distinction might arise because high-volatility regimes generally characterize periods in which large changes occur in the asset rates of return, upward or downward (Rey et al. 2014). 


\section{Figure 7. Impulse responses to Nikkei 225 shock}

(over 20 day periods)

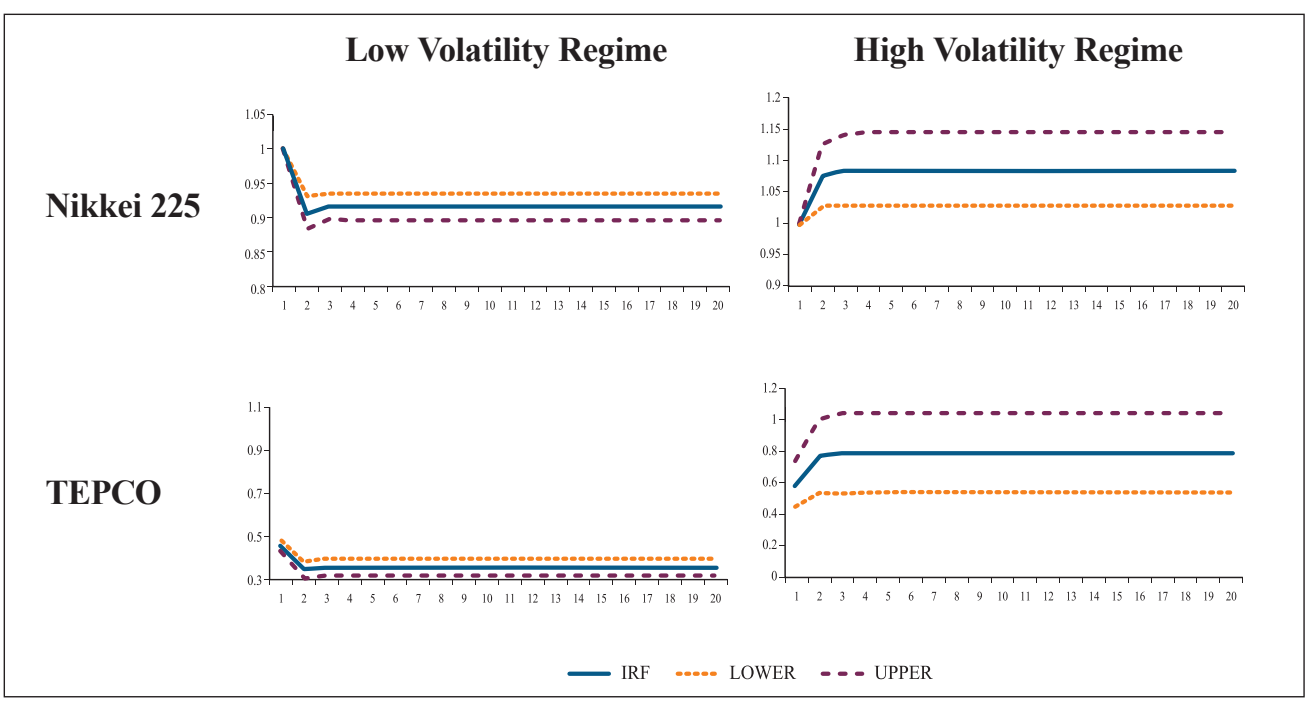

(Note) It plots the 20-day impulse responses of Nikkei 225 shock. Impulse responses appear as solid lines (IRF) and 95-percent confidence intervals appear as dotted lines (LOWER and UPPER).

Figure 8 plots the impulse responses to a shock in TEPCO returns. We note a strong increase of standard deviations in the high-volatility regime, but the shock has no significant impact on the Nikkei. This result confirms that the events that affected TEPCO have had little influence on the Japanese stock market. We can also interpret the results of the bivariate model in terms of Granger causality such that that the Nikkei index frequently causes TEPCO stock price, whereas TEPCO does not cause the Nikkei. This finding also implies that even if the Fukushima catastrophe had a strong impact on TEPCO and the electricity sector as a whole, its impact on the rest of the economy was limited, as reflected by the behavior of the stock market index. 


\section{Figure 8. Responses to TEPCO shock}

(over 20 day periods)

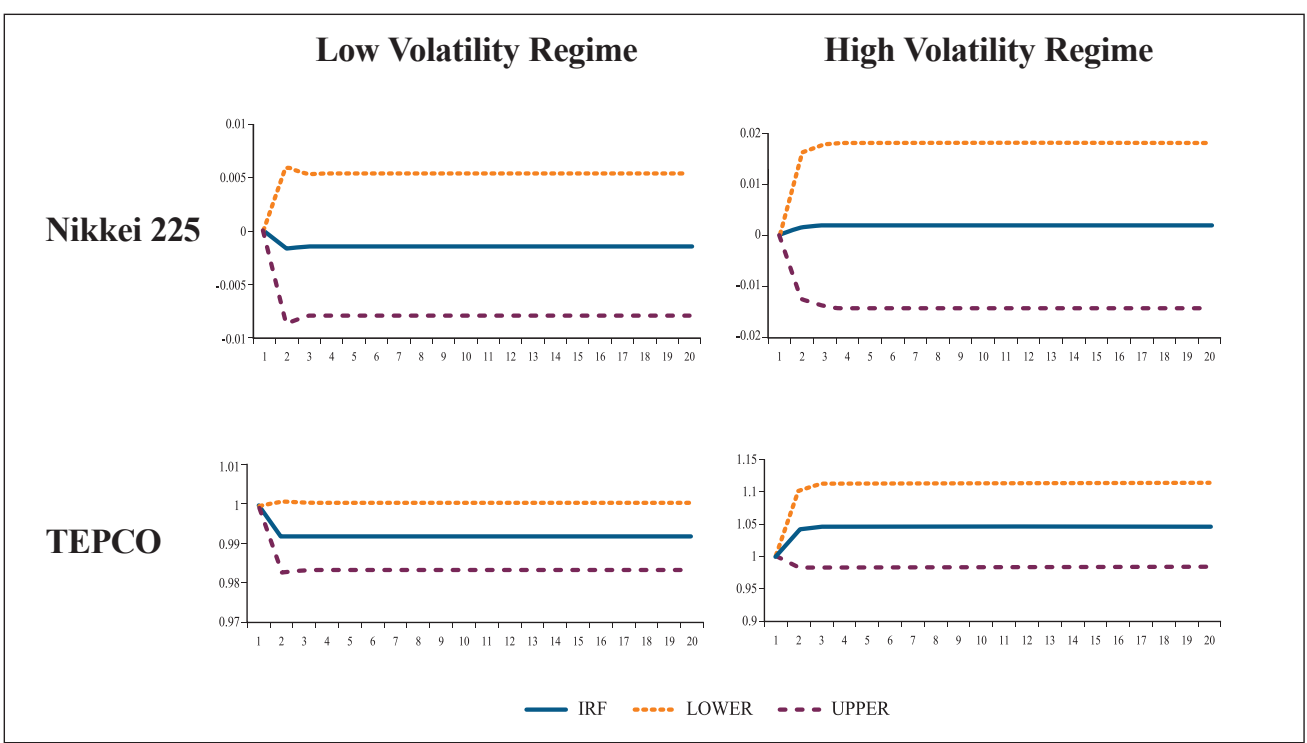

(Note) It plots the 20-day impulse responses of TEPCO shock. Impulse responses appear as solid lines (IRF) and 95-percent confidence intervals appear as dotted lines (LOWER and UPPER).

\section{Conclusion}

Since the early 1980s, the Japanese financial market has been severely disrupted by various shocks, including stock market crashes, a real estate bubble burst, the Asian crisis, the subprime crisis, and recently, the Fukushima disaster. In this work, we seek to verify whether the Fukushima catastrophe had a specific impact, by analyzing the correlations between TEPCO stock price and the Nikkei 225 index. Using regimeswitching models, we show that though the great earthquake had a specific effect on the volatility of TEPCO, it does not appear to have had a lasting impact on the Japanese stock market as a whole. Moreover, the correlation between TEPCO stock returns and the Nikkei 225 returns does not indicate a particular behavioral change, such as a regime switch, as a result of the Fukushima disaster. 
This study led to a more detailed investigation of the relationship between the Japanese stock return, based on the Nikkei 225 index, and a company stock return that suffered an exceptionally large negative shock. The correlations studies show that although the TEPCO shock is considerable, it has not affected the market as a whole. This point has been clarified by using models with a change of regime. Periods with a probability of high correlation are well-identified; from early 1980s to mid-1990s; mid2000s and 2010s. Conversely, the low-correlation regime dominated in the late 1990s and during the dot.com crisis, as well as after the subprime crisis, including the Fukushima period. In addition, the study of impulse responses to a TEPCO shock show that the impact on the Nikkei is low, regardless of the high or low volatility regime. Based on these observations, it can be concluded that a shock, however important it may be, may not have an overall impact when it affects an industrial enterprise, even if it is a leader in its sector. In the case of the Fukushima disaster, it is likely that on the one hand, the market anticipated a rescue of TEPCO by the Japanese State, and on the other hand, it anticipated that the fall in nuclear power production would be quickly compensated by other sources of energy.

Our findings pertaining to the returns, volatilities, and potential causal relationship between the Nikkei index and TEPCO help clarify the long-run volatility process of these series. With these findings, investors can make better-informed choices.

Received 28 September 2017, Revised 15 January 2018, Accepted 29 January 2018 


\section{References}

Bai, Y., Perron, P. Estimating and testing linear models with multiple structural changes. Journal of Econometrics, 66 (1) (1998): 47-78.

Bai, Y., Perron, P. Critical values for multiple structural change tests. Econometrics Journal, 6 (2003a): 72-78.

Bai, Y., Perron, P. (2003b). Critical values for multiple structural change tests. Unpublished tables, manuscript, Boston University.

Bai, Y., Perron, P. Computation and analysis of multiple structural change models. Journal of Applied Econometrics, 18 (2003c): 1-22.

Balcilar, M., Gupta, R., Miller, S.M. Regime switching model of US crude oil and stock market prices: 1859 to 2013. Energy Economics, 49 (2015): 317-327.

Billio, M., Caporin, M. Multivariate Markov switching dynamic conditional correlation GARCH representations for contagion analysis. Statistical Methods and Applications, 14 (2005): 145-161.

Boudt, K., Daníelsson, J., Koopman, S.J., Lucas, A. (2012). Regime switches in the volatility and correlation of financial institutions". National Bank of Belgium, Working paper No. 227.

Capiello, L., Engle, R.F., Sheppard, K. Asymmetric dynamics in the correlations of global equity and bond returns. Journal of Financial Econometrics, 4(4) (2006): 537572.

Cont, R. Empirical properties of asset returns: stylized facts and statistical issues. Quantitative Finance, 1 (2001): 223-236. 
Ding, Z., Granger, C.W.J., Engle, R.F. A long memory property of stock market returns and a new model, Journal of Empirical Finance, 1 (1993): 83-106.

Ehrmann, M., Ellison, M., Valla, N. Regime-dependent impulse response functions in a Markov-Switching Vector Autoregression model. Economics Letters, 78 (2003): 295299.

Engle, R.F. Dynamic conditional correlation: A simple class of multivariate GARCH models. Journal of Business and Economic Statistics, 20 (2002): 339-350.

Garcia, R., Perron, P. An analysis of the real interest rate under regime shifts. Review of Economics and Statistics, 78 (1996): 111-125.

Günay, S. Markov Regime Switching Generalized Autoregressive Conditional Heteroskedastic Model and volatility modeling for oil returns. International Journal of Energy Economics and Policy, 5(4) (2015): 979-985.

Hamilton, J.D. A new approach to the economic analysis of nonstationary time series and the business cycle. Econometrica, 57 (1989): 357-384.

Hahn, M., Frühwirth-Schnatter, S., Sass, J. Markov Chain Monte Carlo methods for parameter estimation in multidimensional continuous time Markov switching models. Journal of Econometrics, 8(1) (2010): 88-121.

Hatase, M., Shintani, M., Yabu, T. (2013). Great earthquakes, exchange rate volatility and government interventions. Vanderbilt University Department of Economics Working Papers, VUECON-13-00007.

Jaussaud, J., Nivoix, S., Rey, S. The Great East Japan Earthquake and stock price. Economic Bulletin, 35-2 (2015): 1237-1261.

Johansen, S. Statistical analysis of cointegration vectors. Journal of Economic Dynamics and Control, 12, issue 2-3 (1988): 231-254. 
Johansen, S. (1996). Likelihood-based inference in Cointegrated Vector Autoregressive models, 2nd ed. Oxford University Press, Oxford.

Johansen, S., Mosconi, R., Nielsen, B. Cointegration analysis in the presence of structural breaks in the deterministic trend. Econometrics Journal, 3 (2000): 216- 249.

Joyeux, R. How to deal with structural breaks in practical cointegration analysis? In B. B. Rao (ed.), Cointegration for the applied economist, second ed. Palgrave Macmillan, New York, (2007): 195-221.

Krolzig, H-M. (1997). Markov-Switching Vector Autoregressions, Lecture Notes in Economics and Mathematical Systems, Springer.

Lee, J., Strazicich, M.C. "Minimum Lagrange Multiplier Unit Root with Two Structural Breaks", Review of Economics and Statistics, 85(4) (2003): 1082-1089.

Lee, J., Strazicich, M.C. Minimum LM unit root with one structural break. Economics Bulletin, 33(4) (2013): 2483-2492.

Lumsdaine, R.L., Papell, D.H. "Multiple trend breaks and the unit root hypothesis" Review of Economics and Statistics, 79 (1997): 212-218.

MacKinnon, J.G., Haug, A.A., Michelis, L. Numerical distribution functions of likelihood ratio tests for cointegration. Journal of Applied Econometrics, 14 (1999): 563-577.

Marcucci, J. Forecasting stock market volatility with regime-switching GARCH models. Studies in Nonlinear Dynamics and Econometrics, 9 (2005): 1-53.

Pelletier, D. Regime switching for dynamic correlations Journal of Econometrics, 131 (2006): 445-473.

Rey, C., Rey, S., Viala, J.-R. Detection of high and low states in stock market returns 
Dynamics of Tokyo Electric Power Company and the Nikkei: 1985 to 2016 including the Fukushima disaster

with MCMC method in a Markov switching model. Economic Modelling, 41(C) (2014): 145-155.

Shiller, R. J. (2005). Irrational exuberance, $2^{\text {nd }}$ ed., Princeton University Press.

Sims, C. Macroeconomics and reality. Econometrica, 48(1) (1980): 1-48. 


\section{Appendices}

\section{Appendix 1: Conditional standard deviations}

To compute volatility for both the Nikkei and TEPCO returns, we estimate various GARCH models. To save space, we have omitted detailed results, but we note that the higher log-likelihoods are obtained for APGARCH or Asymmetric Power Generalized Autoregressive Conditional Heteroscedasticity model. This model, introduced by Ding, Engle and Granger (1993) captures volatility clustering. The APGARCH model includes a leverage term, which allows positive and negative shocks of equal magnitude to produce an unequal response from the market. In other terms, good news and bad news have different predictability for future volatility. Figures A1 and A2 plot the conditional standard deviations/volatilities for this model. 
Figure A1. TEPCO APGARCH(1,1) standard deviation

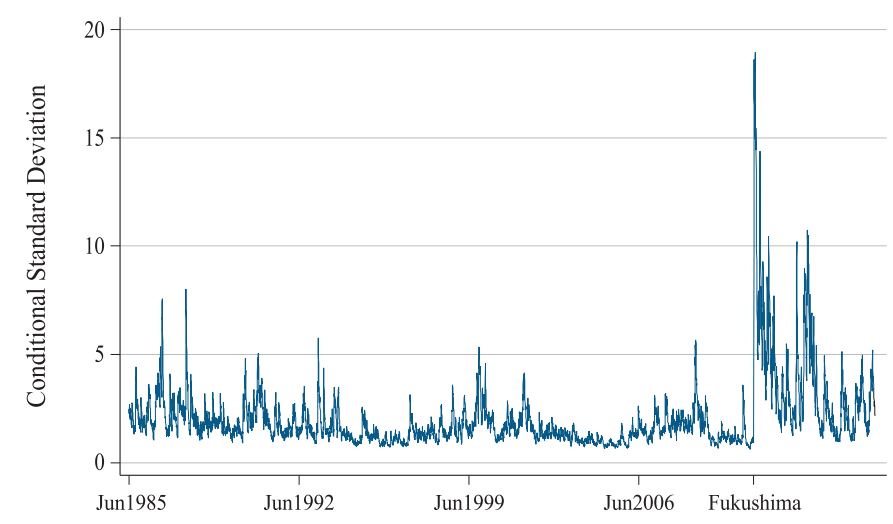

Figure A2. Nikkei APGARCH(1,1) standard deviation

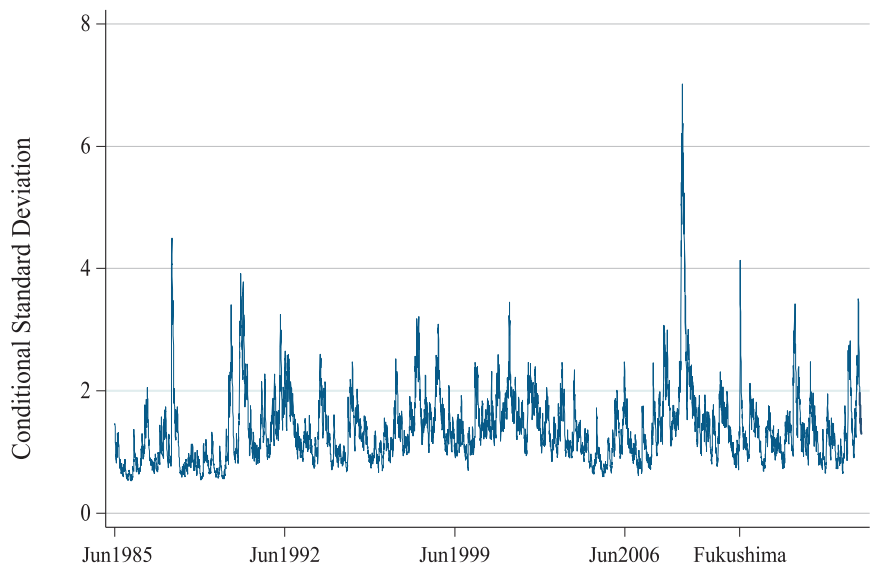




\section{Appendix 2: Regime-switching dynamic correlation/Pelletier model}

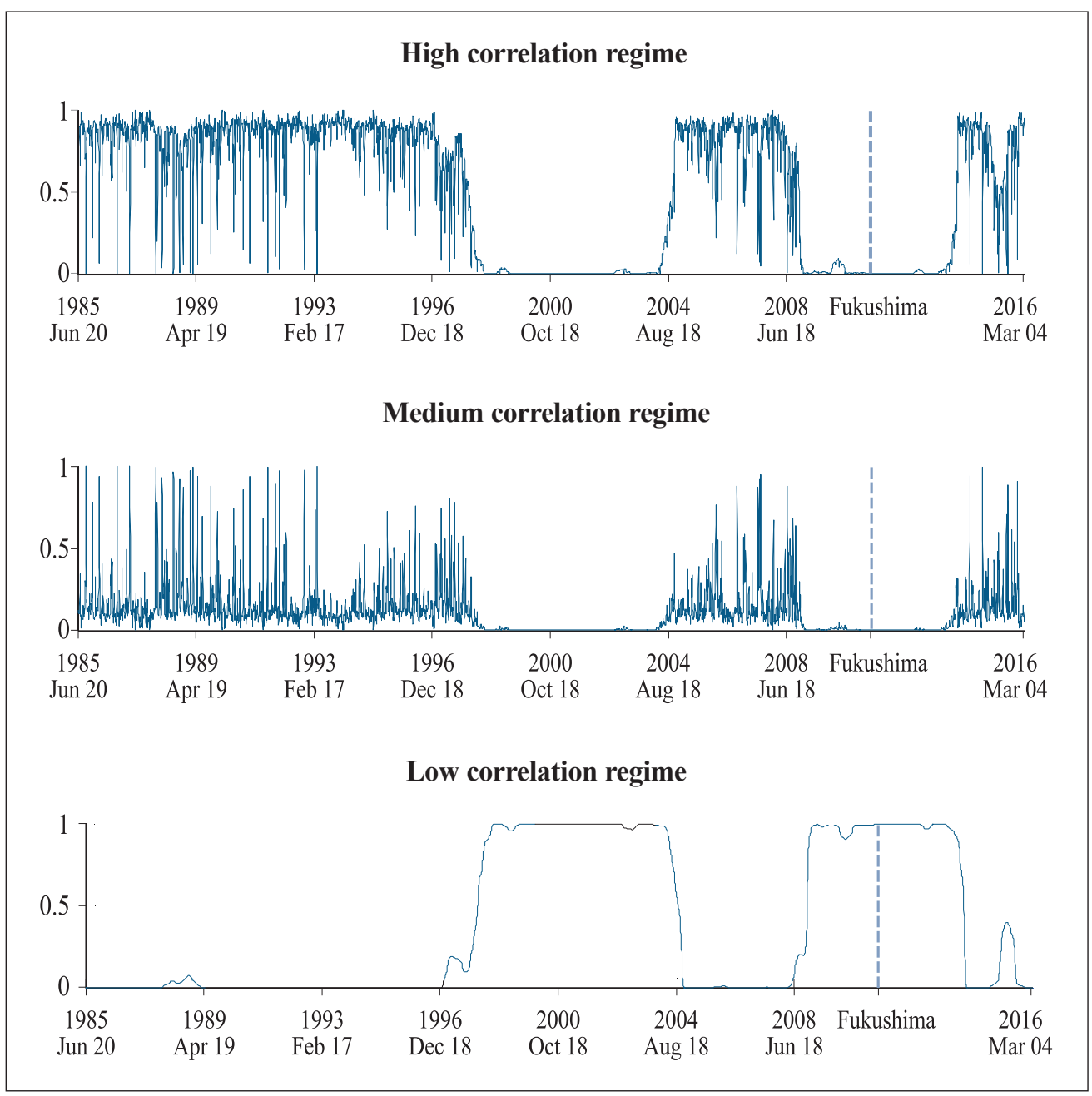

